\title{
Feedback Inhibition of Aldose Reductase Gene Expression in Rat Renal Medulla Galactitol Accumulation Reduces Enzyme mRNA Levels and Depletes Cellular Inositol Content
}

\author{
Carolyn Bondy," Benjamin D. Cowley, Jr., ' Susan L. Lightman," and Peter F. Kador"l \\ *Developmental Endocrinology Branch, ${ }^{\ddagger}$ Laboratory of Kidney and Electrolyte Metabolism, and \\ "Molecular Pharmacology Section, National Institutes of Health, Bethesda, Maryland 20892; and \\ §Institute of Ophthalmology, Moorfield's Eye Hospital, London, United Kingdom
}

\begin{abstract}
Aldose reductase (AR) is an enzyme responsible for converting glucose into sorbitol and galactose into galactitol. In the renal inner medulla, where sorbitol production plays a role in cellular osmoregulation, AR gene expression has been shown to be osmotically regulated. The present study examined the effects of the accumulation of the AR end product, galactitol, induced by galactose feeding, on AR gene expression and on the balance of other cellular osmolytes, including inositol, in the renal medulla. To differentiate between the effects of excess substrate, product, and intervening osmotic factors, rats were fed either control, galactose, galactose and sorbinil (an AR inhibitor), or control plus sorbinil diets. Renal papillae were assayed for AR mRNA, sodium, urea, galactose, galactitol, sorbitol, inositol, and other organic osmolytes. Galactose feeding resulted in a great accumulation of galactitol and reduction in AR mRNA levels in renal papillae. Associated with these changes was a significant depletion of renal papillary sorbitol, inositol, and glycerolphosphocholine. These effects were largely attenuated by sorbinil. The present findings suggest that renal cellular accumulation of the enzyme's polyol product causes downregulation of AR gene expression. Furthermore, our findings suggest that the inositol depletion associated with sorbitol or galactitol accumulation in various cell types during hyperglycemia may be a function of cellular osmoregulation. ( $J$. Clin. Invest. 1990. 86:1103-1108.) Key words: aldose reductase $\bullet$ sorbitol $\bullet$ galactose $\bullet$ galactitol $\bullet$ polyol
\end{abstract}

\section{Introduction}

Aldose reductase (AR, ${ }^{1} \mathrm{EC} 1.1 .121$ ) is a cytosolic enzyme that catalyzes the reduction of aldoses such as glucose and galactose into polyhydric alcohols, or polyols. The reduction of glucose yields sorbitol, while galactose yields galactitol. AR-catalyzed sorbitol production in the cells of the renal inner medulla serves a physiological osmoprotective function. Cells of the inner medulla are exposed to extreme extracellular hypertonicity as a function of the urinary concentrating mechanism. The intracellular accumulation of osmotically active organic

Address reprint requests to Dr. C. Bondy, Building 10, Room 10N262, National Institutes of Health, Bethesda, MD 20892.

Received for publication 12 March 1990 and in revised form 24 May 1990.

1. Abbreviations used in this paper: AR, aldose reductase; GPC, glycerolphosphocholine.

The Journal of Clinical Investigation, Inc.

Volume 86, October 1990, 1103-1108 molecules such as sorbitol helps to balance high extracellular osmolality and maintain cell volume, while preserving a normal intracellular ionic milieu (1). Consistent with this physiological role is the observation that the highest tissue levels of AR mRNA are found in the renal papilla $(2,3)$, where interstitial osmolality may reach 2,000 mosmol/liter or greater. Furthermore, AR gene expression in the renal medulla is regulated in concordance with local tonicity, i.e., increased in antidiuretic extremes of hypertonicity and decreased during states of diuresis when papillary sodium (the primary determinant of papillary osmotic pressure) is reduced $(2,3)$.

The present study used a diet-induced galactosemia model to examine the effects of the accumulation of the AR end product, galactitol, on renal medullary AR gene expression and on the balance of other osmolytes such as inositol. Galactose feeding is a powerful tool for the study of AR regulation because AR has a higher affinity for galactose than for glucose, and because galactitol is not further metabolized or transported $(4,5)$ and thus accumulates inside AR expressing cells. Initial studies showed that galactose feeding resulted in a dramatic increase in renal medullary galactitol and a profound decrease in renal medullary AR mRNA levels, suggesting downregulation of AR mRNA levels in response to AR end product accumulation. However, galactose feeding also caused a significant osmotic diuresis, raising the possibility that the decrease in AR message was due to changes in papillary sodium content as a result of the osmotic diuresis. To distinguish between these possibilities, the study was repeated using an AR inhibitor, sorbinil, to inhibit the production of polyol without affecting the galactose-induced osmotic diuresis or other direct effects of galactose. Papillary levels of sodium, urea, galactitol, sorbitol, inositol, and other osmolytes were measured to elucidate the relationship between AR gene expression and tissue levels of substrate, polyols, and osmolality.

\section{Methods}

Experimental animals. Female Sprague-Dawley rats ( $75 \mathrm{~g})$ were randomly assigned to receive normal rat chow, chow containing $50 \%$ galactose (Bio-Serv, Inc., Frenchtown, NJ), $50 \%$ galactose plus $0.04 \%$ sorbinil, or control chow with $0.04 \%$ sorbinil for $10 \mathrm{~d}$. Average intake of sorbinil delivered in this manner was $50 \mathrm{mg} / \mathrm{kg}$ per d. Sorbinil was provided by Pfizer Central Research, Groton, CT. Access to food and water was ad lib. and care was taken to ensure that water supplies were adequate in the face of the osmotic diuresis that ensued about $12 \mathrm{~h}$ after the initiation of galactose and galactose plus sorbinil diets. Animals were killed after $10 \mathrm{~d}$ and kidneys were rapidly removed and frozen over dry ice. Measurements of AR mRNA, Na, urea, galactose, polyols, and other osmolytes were made using just the papillary portion of the renal inner medulla.

Biochemical analyses. For determination of renal papillary osmolyte content, the two papillae from each experimental animal were 
pooled and homogenized in 7\% perchloric acid. Precipitated protein was removed by centrifugation, redissolved in $10 \%$ SDS, and protein concentration was measured by the BCA protein assay (Pierce Chemical Co., Rockford, IL) using bovine serum albumin as a standard. Perchloric acid supernatants were neutralized to $\mathrm{pH}$ 6-7 with $\mathrm{KOH}$ and frozen at $-80^{\circ} \mathrm{C}$; precipitated perchloric salts were removed by centrifugation. Supernatants were passed through a C-18 column (Bond Elut, Analytichem International, Inc., Harbor City, CA) and $0.22 \mu \mathrm{m}$ filter. Sodium was measured in these samples by flame photometry. Urea, sorbitol, galactose, galactitol, inositol, and other osmolytes were measured by HPLC using a Sugar-Pak column (Waters Associates, Millipore Corp., Milford, MA), as previously described in detail (6).

Determination of $A R$ mRNA levels. Quantitative in situ hybridization histochemistry for detection of renal medullary AR mRNA was performed on the right kidney of experimental animals as follows. $15-\mu \mathrm{m}$-thick sections were cut through the midsection of each kidney containing the renal papilla at $-15^{\circ} \mathrm{C}$. The sections were thawmounted onto gelatinized slides and stored at $-70^{\circ} \mathrm{C}$ until hybridization. The specificity of our antisense oligonucleotide probe (AR1) has previously been characterized (2); in brief, two oligonucleotides complementary to different portions of the rat AR cDNA sequence (AR1 and AR2) produced identical patterns of hybridization throughout a range of tissues, corresponding to cell types previously shown to express the enzyme either by specific immuno- or activity assays, and produced a single band of appropriate size on Northern blot analysis. AR 1 was $3^{\prime}$ end-labeled by incubation $\left(5 \mathrm{~min}\right.$ at $\left.37^{\circ} \mathrm{C}\right)$ with ${ }^{35} \mathrm{~S}$-dATP ( $1 \mu \mathrm{M} ; 1,300 \mathrm{Ci} / \mathrm{mmol}$, New England Nuclear, Boston, MA) and terminal deoxynucleotidyl transferase (100 U; Bethesda Research Laboratories, Bethesda, MD) to a specific activity of 7,000-15,000 Ci/ $\mathrm{mmol}$. Before hybridization, sections were warmed to $25^{\circ} \mathrm{C}$, fixed in $4 \%$ formaldehyde, and soaked for $10 \mathrm{~min}$ in $0.25 \%$ acetic anhydride/ $0.1 \mathrm{M}$ triethanolamine hydrochloride $/ 0.9 \% \mathrm{NaCl}$. Tissue was then dehydrated through an ethanol series, delipidated in chloroform, rehydrated, and air dried. Each slide was hybridized in a complex buffer containing $4 \times$ SSC $(600 \mathrm{mM} \mathrm{NaCl} / 60 \mathrm{mM}$ sodium citrate, $\mathrm{pH} 7.0)$ and labeled antisense oligonucleotide probe $\left(\approx 5 \times 10^{6} \mathrm{cpm} / \mathrm{ml}\right)$ for $16 \mathrm{~h}$ at $37^{\circ} \mathrm{C}$ in humid chambers. Slides were washed four times (15min cycles) in $2 \times \mathrm{SSC} / 50 \%$ formamide at $40^{\circ} \mathrm{C}$, followed by two 1 -h washes in $1 \times \mathrm{SSC}$ at $25^{\circ} \mathrm{C}$.

All sections from a given experiment were hybridized in the same incubation and exposed together against a single film (Hyperfilm ${ }^{\mathrm{TM}}$ beta-max; Amersham Corp., Arlington Heights, IL) along with autoradiographic standards $\left({ }^{14} \mathrm{C}\right.$ Micro-scales; Amersham). The period of exposure was adjusted so that all density values fell within the linear portion of the standard curve and were well below saturation (24-48 h). Some slides were dipped in Kodak NTB-3 nuclear track emulsion, stored desiccated at $4^{\circ} \mathrm{C}$ for $3 \mathrm{~d}$, developed in Kodak Dektol at $15^{\circ} \mathrm{C}$, and counterstained with hematoxylin and eosin for microscopic evaluation.

Levels of AR mRNA were quantified using film autoradiographs and computer-assisted densitometry in a system previously described in detail (2). Three anatomically matched sections representing the mid-portion of the renal papilla from each animal were analyzed. All images were digitized and electronically stored in one session to ensure uniform accession conditions. Mean papillary density values for each experimental animal were obtained and these values were used in an analysis of variance (ANOVA) between the different groups. Results are expressed as percentage of control density \pm SEM.

Statistical analysis. Data from experiment one (control group 1 and galactose fed) were analyzed by unpaired $t$ test. Data from experiment two (control group two, galactose plus sorbinil and sorbinil-only groups) were analyzed by one-way ANOVA; when significant differences were detected, specific group differences were identified using Fisher's protected least significant difference test. In addition, data from both experiments were analyzed by normalizing values to contemporary controls. Control group 2, galactose-fed, galactose plus sorbinil, and sorbinil-only groups were analyzed by two-way ANOVA.
When an interaction between the galactose and sorbinil was detected, differences between the galactose and sorbinil group and galactose-fed or sorbinil-only groups were analyzed by pairwise $t$ tests between groups overall, controlling for type I error by adjusting the level of significance by the Bonferroni procedure.

\section{Results}

The pattern of AR gene expression in the kidneys of rats maintained on control diets is distinctive, as shown in Fig. 1 (top). AR mRNA levels are highest in the renal papilla, and diminish in parallel with the cortico-papillary osmotic gradient. In the renal cortex, where local osmolality is equal to that of plasma, AR mRNA is below the limits of detection (Figs. 1 and 2). Sections were exposed for prolonged periods of time to $x$-ray film or autoradiographic emulsion to determine if any specific AR mRNA signal would become evident in the cortex of control or experimental kidneys, but the hybridization signal did not exceed background. Galactose feeding resulted in a dramatic reduction in levels of renal papillary AR mRNA (Fig. 1, bottom). Quantitative analysis of in situ hybridization autoradiographs showed that AR mRNA in papillae from galactose-fed rats was reduced by $\sim 60 \%$ compared with papillae from control-diet rats (Fig. $3 \mathrm{~B}$ ). AR mRNA in papillae from galactose plus sorbinil animals, however, was not significantly different from control (Fig. $3 \mathrm{~B}$ ). Sorbinil added to control diet did not significantly change papillary AR mRNA levels, although there was a suggestion of an increase over control.

Galactose content was comparable in the galactose and galactose plus sorbinil papillae, and undetectable in control and sorbinil-alone papillae (Table I). Galactitol was undetectable in control papillae, but present at high levels in the papillae from galactose-fed rats. Sorbitol was decreased in papillae with high galactitol levels, but the total AR polyol content was still much greater than control (Fig. $3 \mathrm{~A}$ ). Sorbinil treatment resulted in an $\sim 70 \%$ reduction in total AR product, comparing levels of sorbitol in papillae from animals fed control chow with levels in papillae from those fed control chow with sorbinil (a $65 \%$ reduction), and comparing galactitol plus sorbitol levels in papillae from rats receiving galactose-containing chow with galactitol plus sorbitol levels in papillae from galactose plus sorbinil-fed rats (a $74 \%$ reduction). The result of this inhibition was that, in the galactose plus sorbinil-diet papillae, the sum of AR-produced polyols was equivalent to that in control-diet papillae.

Inositol and glycerolphosphocholine (GPC), two major renal osmolytes, were markedly decreased in papillae from galactose-fed rats; sorbinil treatment restored levels of both to $\sim 60 \%$ of control (Table I). Another significant renal osmolyte, betaine, was unchanged except in the galactose plus sorbinil-fed group, where it was significantly increased. Papillae from rats fed control chow plus sorbinil-diet had a significant reduction in sorbitol levels and an increase in inositol content (Table I). Fig. 3 illustrates the decreases in papillary AR mRNA and inositol in relation to increases in AR-product content.

Sodium levels were increased in papillae of galactose-fed and galactose plus sorbinil-fed rats. Urea content was decreased in galactose papillae, compared with control group 1, a finding that may be explained by the osmotic diuresis associated with galactosemia. However, urea content was not de- 


\section{Control}
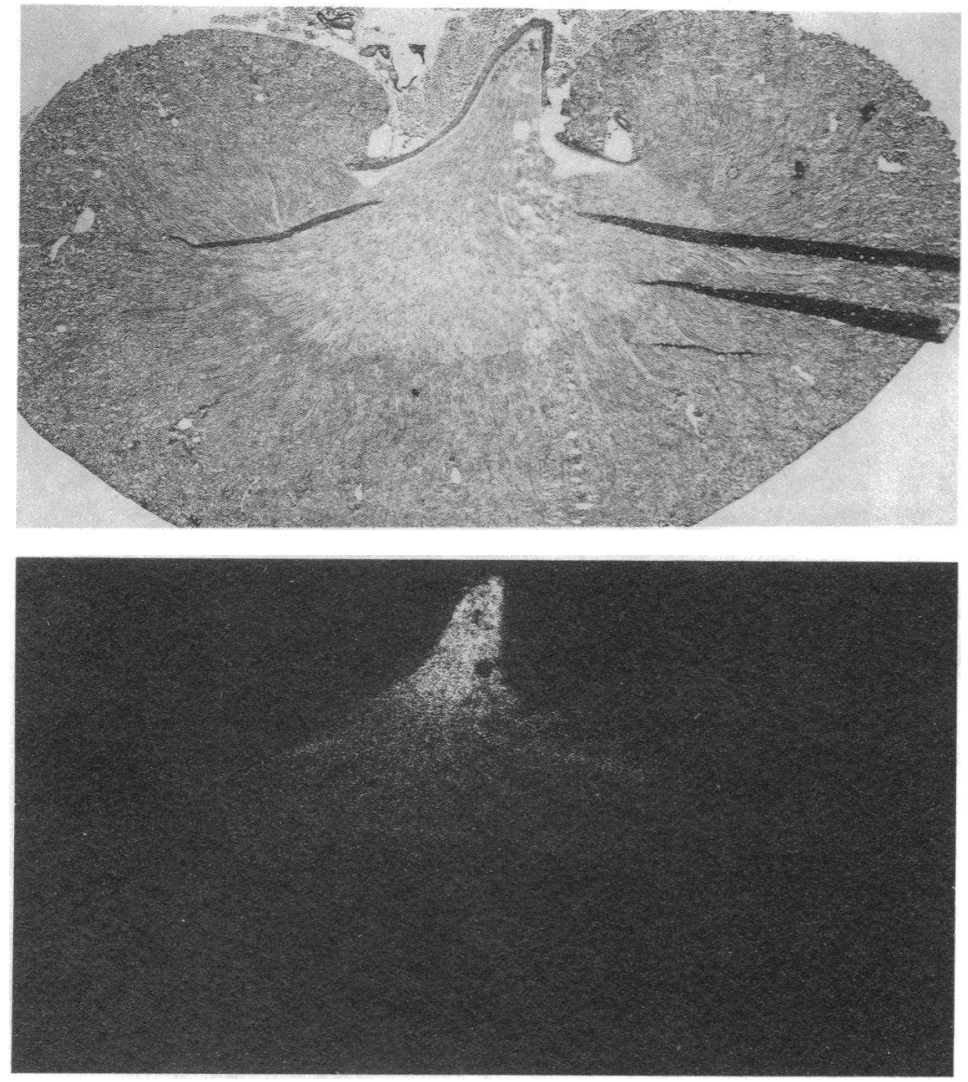

\section{Galactose}
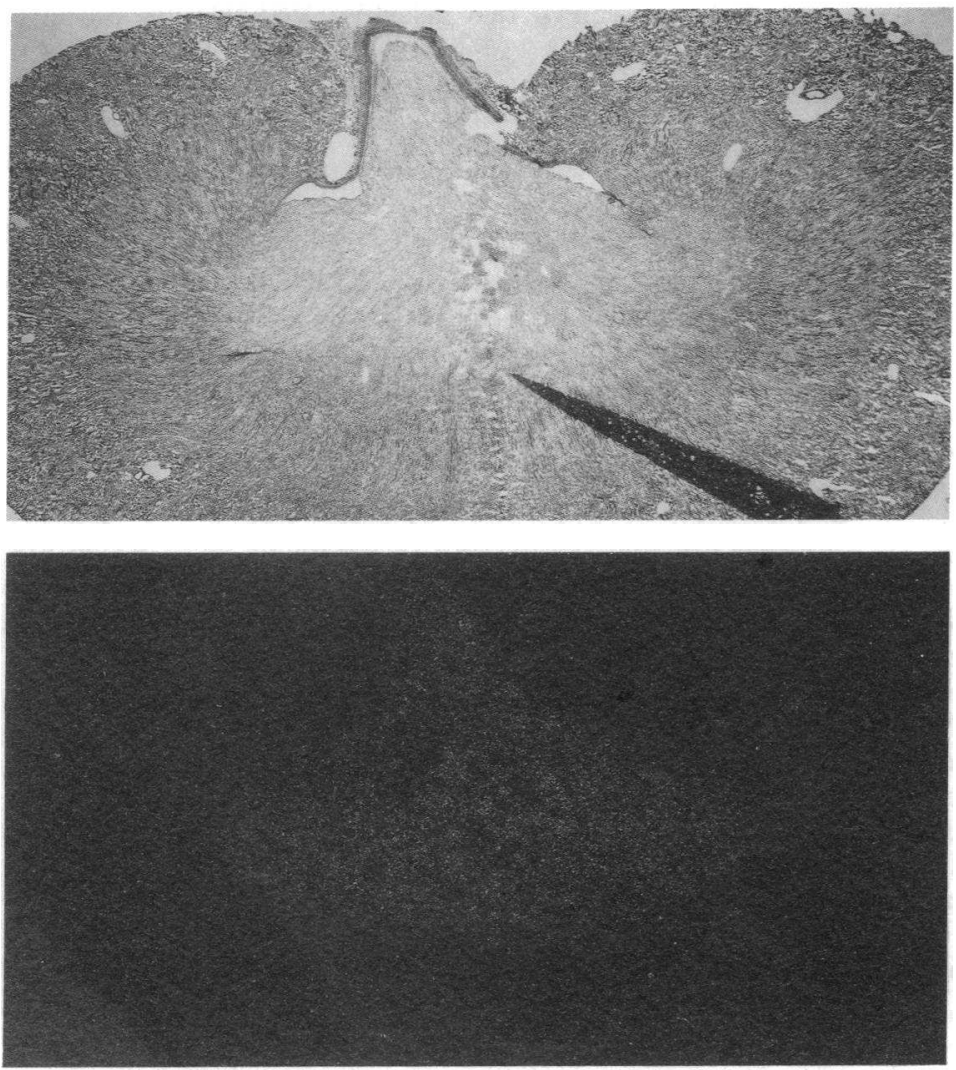

Figure 1. AR mRNA shown by in situ hybridization in rat kidney. The top shows a representative tissue section paired with its corresponding autoradiograph from a control ani$\mathrm{mal}$, and the bottom shows a similar section from an animal fed galactose-containing chow for $10 \mathrm{~d}$. These sections were hybridized in the same incubation and exposed against the same piece of film. Hybridization to AR mRNA is detected only in the inner medulla, with the most intense signal in the papillary portion. The papilla is the protuberant portion of the inner (white) medulla. (The $x$ ray was used as a negative to make the picture, so areas exposed by the radiolabeled probe appear white.) 

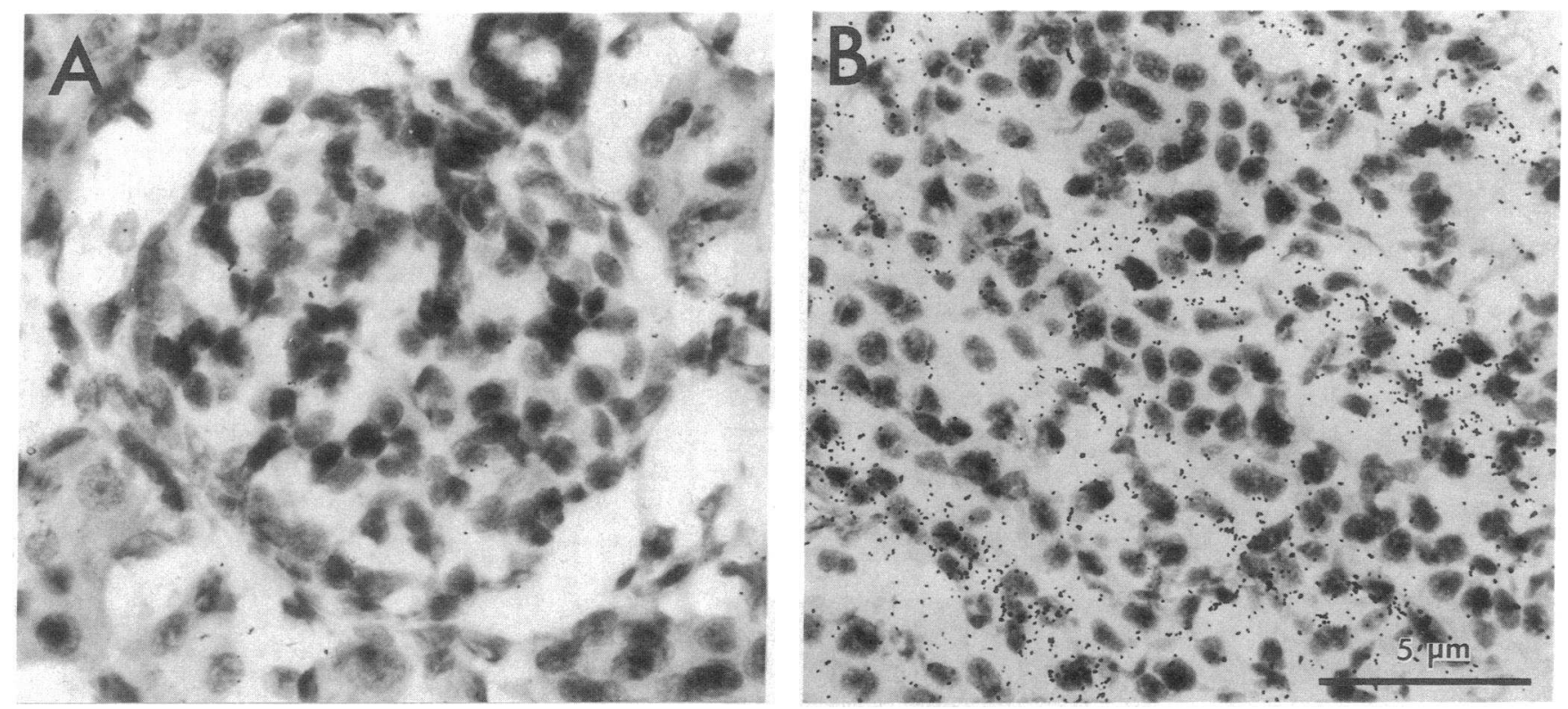

Figure 2. Photomicrographs from glomerular $(A)$ and inner medullary $(B)$ regions of a control kidney section showing hybridization grains, appearing black, over the tubular epithelial cells of the inner medulla. Sparse grains in the glomerulus are indistinguishable from background signal level.
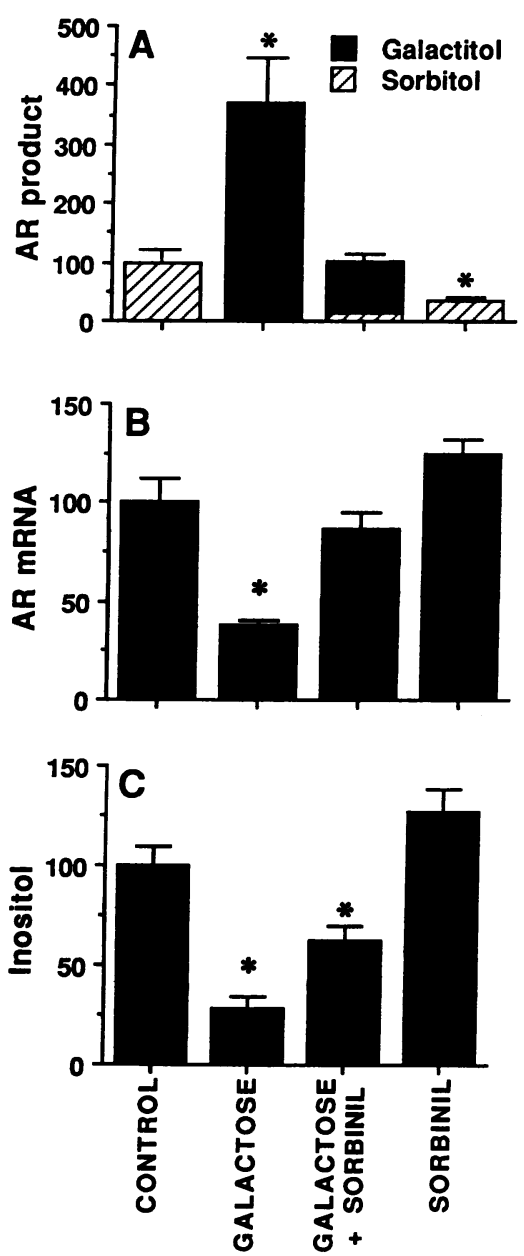

Figure 3. Relationship of renal papillary AR end product (sorbitol + galactitol) to AR mRNA levels and inositol content. $(A)$ Papillary content of galactitol and sorbitol, $(B)$ the level of papillary $A R$ mRNA, and $(C)$ the inositol content in the different dietary groups. Rats were fed diets composed of control chow, chow containing $50 \%$ galactose, $50 \%$ galactose with the addition of the AR inhibitor, sorbinil, or sorbinil added to control chow. Data from two series of experiments are combined in these graphs and expressed as mean percent of their respective controls $\pm S E .{ }^{*}$ Indicates significance at a value of $P<0.05$ or less; see Table I for details of statistical analysis. creased in galactose plus sorbinil papillae compared with control group 2, despite the fact that these rats also experienced osmotic diuresis. This may be an effect of sorbinil, since urea was increased in rats fed chow containing sorbinil only.

\section{Discussion}

This study has shown that galactose feeding causes a large accumulation of the AR end product, galactitol, in the cells of the renal papilla, and that this polyol accumulation is associated with a significant decrease in the level of AR mRNA transcripts, and a depletion of other papillary osmolytes, including sorbitol, GPC, and inositol. Evidence that these changes are due specifically to galactitol accumulation and not to other effects of galactose feeding, such as changes in papillary sodium content associated with osmotic diuresis, is found in the normalization of AR mRNA level and near normalization of inositol content produced by sorbinil, which occurred in the face of unaltered galactose and sodium levels. The decrease in sorbitol content in papillae of galactose-fed animals is explained by the approximately 10-fold higher affinity of AR for galactose than for glucose (5), and the presence of galactose in great excess over glucose in these papillae.

The normal stimulus for increased AR-polyol production in the renal medulla is thought to be an increase in intracellular ionic strength resulting from increases in extracellular tonicity occurring during urinary concentration (1). This has been shown to be the case in renal papillary cell cultures where increases in medium $\mathrm{NaCl}$ are followed by early increases in intracellular ion concentration and later increases in AR mRNA levels and enzyme activity resulting in elevation of sorbitol content and normalization of intracellular ionic strength (7-9). Previous studies have shown that conditions of dehydration or diuresis associated with alterations of renal 


\begin{tabular}{|c|c|c|c|c|c|c|c|c|}
\hline & \multirow[b]{2}{*}{$\begin{array}{l}\text { Control } \\
\text { group 1 }\end{array}$} & \multirow[b]{2}{*}{ Galactose diet } & \multirow[b]{2}{*}{$\begin{array}{l}\text { Control } \\
\text { group 2 }\end{array}$} & \multirow[b]{2}{*}{$\begin{array}{c}\text { Sorbinil } \\
\text { only }\end{array}$} & \multirow[b]{2}{*}{$\begin{array}{l}\text { Galactose } \\
+ \text { sorbinil }\end{array}$} & \multicolumn{3}{|c|}{$P$ values (2-way ANOVA)* } \\
\hline & & & & & & $\begin{array}{l}\text { Between } \\
\text { galactose }\end{array}$ & $\begin{array}{l}\text { Between } \\
\text { sorbinil }\end{array}$ & Interaction" \\
\hline & $n=4$ & $n=4$ & $n=3$ & $n=4$ & $n=4$ & & & \\
\hline Galactose & $0 \pm 0$ & $970 \pm 213^{\prime}$ & $0 \pm 0$ & $0 \pm 0$ & $832 \pm 95^{* * \pm \pm}$ & & & \\
\hline Galactitol & $0 \pm 0$ & $1,593 \pm 341^{\pi}$ & $0 \pm 0$ & $0 \pm 0$ & $343 \pm 53^{* * \pm \pm}$ & & & \\
\hline (\% of control sorbitol) & & $369 \pm 79$ & $0 \pm 0$ & $0 \pm 0$ & $88 \pm 14^{\S \S 111}$ & $<0.001$ & $<0.01$ & $<0.01$ \\
\hline Sorbitol & $432 \pm 62$ & $0 \pm 0^{9}$ & $389 \pm 68$ & $136 \pm 5^{* *}$ & $49 \pm 5^{* *}$ & & & \\
\hline (\% of control) & & $0 \pm 0$ & $100 \pm 17$ & $35 \pm 1$ & $13 \pm 1^{\$ \S}$ & $<0.001$ & $<0.01$ & $<0.001$ \\
\hline Inositol & $312 \pm 26$ & $86 \pm 18^{4}$ & $230 \pm 22$ & $293 \pm 27$ & $142 \pm 18^{* * \neq \ddagger}$ & & & \\
\hline (\% of control) & & $28 \pm 6$ & $100 \pm 9$ & $127 \pm 12$ & $62 \pm 8$ & $<0.001$ & $<0.01$ & NS \\
\hline GPC & $844 \pm 91$ & $248 \pm 60^{\prime}$ & $671 \pm 108$ & $676 \pm 43$ & $385 \pm 25^{* * \neq \ddagger}$ & & & \\
\hline (\% of control) & & $29 \pm 7$ & $100 \pm 16$ & $101 \pm 6$ & $57 \pm 4$ & $<0.001$ & NS & NS \\
\hline Betaine & $240 \pm 24$ & $216 \pm 37$ & $233 \pm 50$ & $251 \pm 23$ & $432 \pm 23^{* * \neq \ddagger}$ & & & \\
\hline (\% of control) & & $90 \pm 15$ & $100 \pm 21$ & $108 \pm 10$ & $185 \pm 10^{\S 81111}$ & $<0.05$ & $<0.01$ & $<0.01$ \\
\hline Sodium & $257 \pm 9$ & $323 \pm 14^{\prime \prime \prime}$ & $219 \pm 4$ & $253 \pm 12$ & $262 \pm 13$ & & & \\
\hline (\% of conrol) & & $126 \pm 5$ & $100 \pm 2$ & $115 \pm 6$ & $119 \pm 6$ & $<0.05$ & NS & NS \\
\hline Urea & $225 \pm 51$ & $88 \pm 13^{n}$ & $104 \pm 29$ & $263 \pm 70^{* *}$ & $87 \pm 9^{\ddagger \ddagger}$ & & & \\
\hline (\% of control) & & $39 \pm 6$ & $100 \pm 28$ & $253 \pm 67$ & $83 \pm 9$ & $<0.01$ & $<0.05$ & NS \\
\hline
\end{tabular}

Values are means $\pm \mathrm{SE}$. Sodium and urea in $\mu \mathrm{mol} / \mathrm{g}$ wet $\mathrm{wt}$, other values in $\mu \mathrm{mol} / \mathrm{g}$ protein. ${ }^{*}$ Data from both experiments were normalized to contemporary controls and analyzed by 2-way ANOVA. Significant values indicate: ${ }^{\ddagger}$ An effect of galactose on the parameter measured. ${ }^{\S}$ An effect of sorbinil on the parameter measured. "An interaction between galactose and sorbinil in their effects of the parameter measured. If a significant interaction was detected, the galactose + sorbinil group was compared to the galactose diet group and the sorbinil only group by $t$ test (see Methods). ' $P<0.005$ compared to control group 1 by unpaired $t$ test. Data from the 2 nd experiment only were analyzed by 1 -way ANOVA. ** Different from control group 2. " ${ }^{\ddagger}$ Different from sorbitol only. \$ Different from sorbitol only. "II" Different from galactose diet. " $P<0.05$

medullary tonicity (primarily extracellular sodium) are associated with corresponding changes in the medullary AR mRNA concentration $(2,3)$, enzyme activity, and sorbitol content $(3,10,11)$, suggesting that a similar regulatory mechanism occurs in vivo.

To further elucidate the mechanisms governing AR gene expression and osmoregulation in renal papillary cells, the present experiments have used the fact that AR catalytic rate is highly dependent on substrate concentration, and that AR has a high affinity for the substrate galactose, to induce AR-polyol accumulation in the absence of a primary osmotic stimulus. Under these circumstances, it would be expected that galactitol accumulation causes osmotically driven water entry, resulting in a relative dilution of intracellular ionic strength. Given that increases in intracellular ionic strength have been shown to increase AR transcript levels $(7,8)$, reduced intracellular ion concentration may trigger a reduction in AR transcripts. The mechanism by which cellular ion concentration modulates AR mRNA levels is unknown, but recent evidence suggests that cytoplasmic ionic strength may itself serve as a "second messenger" to specifically modulate gene expression in response to extracellular osmotic shifts in prokaryotes (12).

The fall in renal papillary inositol and GPC in galactosefed animals may also be attributed to a cellular homeostatic response to elevated galactitol levels. Inositol and GPC are osmotically active organic solutes which are thought to function as osmolytes in the renal medulla, and may increase or decrease in parallel with sorbitol to help balance changes in medullary interstitial sodium $(3,10,11)$. In the present study, when an increase in AR product was induced by substrate excess rather than elevated extracellular osmotic pressure, inositol and GPC content fell. When AR polyol was reduced to control levels by sorbinil treatment, papillary inositol and GPC content increased toward but did not attain control levels (Table I and Fig. 3). The hypothesis that intracellular osmolyte content is still regulated by extracellular sodium is supported by the strong correlation between total compatible osmolytes and papillary sodium seen in the absence of sorbinil (Fig. 4). It is interesting that total compatible osmolytes fell in both sorbinil-treated groups in spite of increased papillary sodium. This suggests that in the presence of sorbinil, the other three known renal medullary compatible osmolytes do not increase to a sufficient extent to replace the lowered sorbitol, and thus sorbinil may impair the renal medulla's volume regulatory mechanisms.

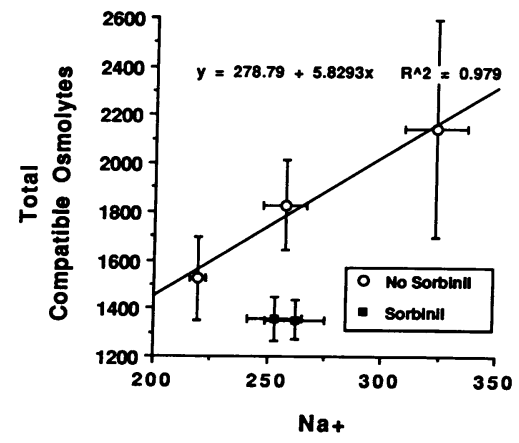

Figure 4. Total compatible osmolyte content versus sodium content in the rat renal papilla. Total compatible osmolytes (sorbitol, galactitol, GPC, betaine, and inositol) are expressed as micromoles per gram protein, and sodium as wet weight. All values are means $\pm \mathrm{SE}$. 
The regulation of papillary betaine is more complex. In previous experiments, both in vitro (13) and in vivo (3), renal cellular betaine accumulation is stimulated by increases in extracellular sodium; however, this increase in betaine accumulation is inhibited by elevated urea concentrations. In the current study, galactose-fed rats had higher papillary sodium and lower urea compared to controls, but betaine content did not change, suggesting that an increase in betaine was obviated by the large increase in galactitol. When AR was inhibited in galactose-fed rats by the addition of sorbinil, the increase in papillary sodium was accompanied by an increase in betaine. In contrast, in rats given sorbinil-only chow, increased papillary sodium was not associated with an increase in betaine; however, papillary urea was increased in these animals. This is consistent with the previous studies $(3,13)$ in which increased urea prevented a rise in cellular betaine in response to elevated extracellular sodium.

These observations on the renal papillary cell response to AR-polyol accumulation suggest a possible explanation for the inositol depletion seen in other tissues such as peripheral nerve $(14,15)$ when excess AR substrate levels result in sorbitol or galactitol accumulation. Cellular inositol levels may be primarily regulated by changes in inositol transport, and a specific, $\mathrm{Na}^{+}$-dependent inositol transporter, with similar characteristics in renal and nervous tissue, has been described (16-18). Because of the observation that inositol uptake is reduced when cells are incubated in the presence of excess glucose or galactose, it has been suggested that the sugars themselves, or their reduced polyol products, directly interfere with inositol transport $(16,17)$. Another possibility, however, given the observations in renal medullary cells, is that inositol transport is independently governed as a function of cellular osmoregulation. Thus, inositol is observed to increase in concert with sorbitol in response to increases in medullary extracellular tonicity $(3,10,11)$, but to decrease when AR-polyol accumulation is a result of substrate excess, rather than extracellular hypertonic stress. The increased cellular inositol content in the former case, and the decreased inositol content in the latter, would both serve to maintain normal cell volume. It is possible, as a matter of speculation, and by analogy with an osmotically regulated, $\mathrm{Na}^{+}$-dependent betaine transporter found in prokaryotes (12), that the inositol transporter is responsive to changes in cell volume.

The present observations are derived from renal medullary cells, which are specialized for the maintenance of the intracellular milieu in an osmotically challenging environment. However, they may also apply to other cell types where ARpolyol accumulation results in inositol depletion, such as nerve, lens, and retinal pericyte $(14,15,19)$. This view integrates the osmotic stress and inositol depletion hypotheses attempting to elucidate the biochemical basis for cellular injury in chronic hyperglycemia.

\section{Acknowledgments}

We wish to thank Dr. Maurice Burg and Dr. Bruce Nisula for helpful discussion and review of the manuscript.

\section{References}

1. Burg, M. B. 1988. Role of aldose reductase and sorbitol in maintaining the medullary intracellular milieu. Kidney Int. 33:635641.

2. Bondy, C. A., S. L. Lightman, and S. L. Lightman. 1989. Developmental and physiologic regulation of aldose reductase mRNA expression in renal medulla. Mol. Endocrinol. 3:1409-1416.

3. Cowley, B. D., J. D. Ferraris, D. Carper, and M. B. Burg. 1990. In vivo regulation of aldose reductase mRNA, protein and sorbitol content in rat renal medulla. Am. J. Physiol. 258:F154-F161.

4. Kinoshita, J. H. 1965. Cataracts in galactosemia. Invest. Ophthalmol. 4:486-499.

5. Kador, P. F. 1988. Pharmacology of aldose reductase inhibitors. Med. Res. Rev. 8:325-352.

6. Wolff, S. D., P. H. Yancey, T. S. Stanton, and R. S. Balaban. 1989. A simple HPLC method for quantitating the major organic solutes of the renal medulla. Am. J. Physiol. 256:F954-F956.

7. Garcia-Perez, A., B. Martin, H. R. Murphy, S. Urchida, H. Murer, B. D. Cowley, J. S. Handler, and M. B. Burg. 1989. Molecular cloning of cDNA coding for kidney aldose reductase: regulation of specific mRNA accumulation by $\mathrm{NaCl}$-mediate osmotic stress. J. Biol. Chem. 264:16815-16821.

8. Uchida, S., A. Garcia-Perez, H. Murphy, and M. B. Burg. 1989. The signal for induction of aldose reductase in renal medullary cells by high external NaCl. Am. J. Physiol. 256:C614-C620.

9. Bagnasco, S. M., H. R. Murphy, J. J. Bedford, and M. B. Burg. 1988. Osmoregulation by slow changes in aldose reductase and fast changes in sorbitol flux. Am. J. Physiol. 254:C788-C792.

10. Bagnasco, S. M., R. Balaban, H. M. Fales, Y.-M. Yang, and M. B. Burg. 1986. Predominantly osmotically active organic solutes in rat and rabbit renal medullas. J. Biol. Chem. 261:5872-5877.

11. Gullans, S. R., J. D. Blumenfeld, J. A. Balschi, M. Kaleta, R. M. Brenner, C. W. Heilig, and S. C. Hebert. 1988. Accumulation of major organic osmolytes in rat inner medulla in dehydration. Am. J. Physiol. 255:F626-634.

12. Higgins, C. F., C. J. Dorman, D. A. Sterling, L. Waddell, I. R. Booth, G. May, and E. Bremer. 1988. A physiologic role for DNA supercoiling in the osmotic regulation of gene expression in S. typhimurium and E. coli. Cell. 52:569-584.

13. Naknishi, T., R. J. Turner, and M. B. Burg. 1989. Osmoregulatory accumulation of betaine by MDCK cells in hyperosmotic medium involves increased betaine transport. Kidney Int. 35:499 (Abstr.)

14. Greene, D. A., S. A. Lattimer, and A. A. F. Sima. 1987. Sorbitol, phosphoinositides and sodium-potassium-ATPase in the pathogenesis of diabetic complications. N. Engl. J. Med. 316:599-605.

15. Nishimura, C., M. F. Lou, and J. H. Kinoshita. 1987. Depletion of myo-inositol and amino acids in galactosemic neuropathy. J. Neurochem. 49:290-295.

16. Hammerman, M. R., B. Sacktor, and W. H. Daughaday. 1980. Myo-inositol transport in renal brush border and its inhibition by glucose. Am. J. Physiol. 239:F113-F120.

17. Segal, S., S. M. Hwang, J. Stern, and D. Pleasure. 1984. Inositol uptake by cultured rat Schwann cells. Biochem. Biophys. Res. Commun. 120:486-492.

18. Yorek, M. A., J. A. Dunlap, and E. M. Leeny. 1989. Effect of galactose and glucose levels and sorbinil treatment on myo-inositol metabolism and Na-K pump activity in cultured neuroblastoma cells. Diabetes. 38:996-1004.

19. Li, W., L. S. Chan, M. Khatami, and J. H. Rockey. 1986. Non-competitive inhibition of myo-inositol transport in cultured bovine retinal capillary pericytes by glucose and inhibition by sorbinil. Biochim. Biophys. Acta. 857:198-208. 